\title{
PRESENTATION OF SPATIAL DATA OF ELECTRIC NETWORKS IN GEO- INFORMATION SYSTEMS
}

\author{
Viktor Yarosh, Alexey Efanov, Sergey Yastrebov, Evgeny Privalov \\ Stavropol State Agrarian University, Russia \\ yarviktor@yandex.ru,yefanov@mail.ru,yastrsergej@yandex.ru, evgraf.stat@yandex.ru
}

\begin{abstract}
Effective management of electrical networks operation is impossible without the use of modern information technologies. Geo-informatics is a rapidly developing trend in information technologies that becomes widely used in the electric power industry. The electrical network in a geometric representation brings up associations with a linear oriented graph. And this is a determining fact for any systems designed to automate information about electrical networks. The primaries are data structures in computer memory, which may or may not be interconnected (contain or not contain topological links). Electrical network diagrams should present in geo-information systems as vector graphics. The vector representation of spatial data can be: non-topological or topological. Vector-non-topological data representation is a digital representation of a point, linear, and polygonal spatial objects as a set of coordinate pairs, with the description of objects geometry only. A vectortopological presentation is a kind of vector presentation of linear and polygonal spatial objects that describes not only their geometry but also the topological relations between polygons, arcs, and nodes. The article describes the advantages and disadvantages of the use of the vector-topological and vector-non-topological presentation of the data of electrical networks. Topological geo-information systems support poorly or do not support at all the object-oriented domain models, and in object geo-information systems the topological relations between objects can be presented in an insufficiently complete form. Development of a hybrid object-topological model of geoinformation systems is a highly relevant task for the application of geo-information systems in the power industry.
\end{abstract}

Keywords: geo-information systems, electrical networks, topology, spatial data.

\section{Introduction}

Effective management of electrical networks is impossible without the use of modern information technology. Geo-informatics is a rapidly developing area of information technologies. GIS (GeoInformation Systems) have characteristics of intuitive display and support efficient spatial analysis and topology analysis.

GIS developing companies offer a large number of different solutions. They vary considerably in their capabilities and in practical applicability for solving problems of managing electrical grids.

The choice of models and the way of data organizing in GIS is much more important than the software package choice, since it has a direct impact on many of GIS functionalities.

Despite a large number of examples of geo-information technologies application in the management of electrical networks reported [1-3], it is important to note that the role of GIS in them most often reduces only to visualization of the network map on a geographical map or terrain plan. At the moment, GIS should solve, apart from information and reference tasks, computational, analytical and operational and management tasks [4]. At the same time, GIS in its pure form cannot solve specific problems of modeling and calculating the electrical networks modes [5].

Most of the process tasks solved in the management of electrical networks require, in addition to information about the spatial position and parameters of electrical equipment, data on the network topology structure. Network topology structure is essential in many advanced applications of DMS (Distribution Management System), such as power flow calculation, load forecasting, network reconfiguration, outage analysis, etc [6;7]. At present, GIS has been widely used in DMS [8;9]. Most of the static data (network topology data) required for advanced applications of DMS are from GIS spatial data. The data models of modern GIS are poorly adapted for describing topological relations to the extent required for an adequate presentation of electrical networks. This will need a method to transform the topology analysis of spatial data described in GIS to the way that the power system can deal with $[10 ; 11]$.

The electrical network in a geometric presentation brings up associations with a linear oriented graph. For electrical networks, an image or graphics in GIS, i.e. the display of diagrams on the monitor screen, paper media is secondary. The primary is the data model that is in the computer memory. Interrelated data structures are stored as address references. It is in the memory of a computer that data 
structures can interconnect or not interconnect (contain topological links or not contain). In any case, the data structures displayed on a computer screen or paper with GIS software will be the same.

\section{Materials and methods}

Presentation of spatial data is a way to digitally describe spatial objects. The vector presentation of spatial data can be: a vector-non-topological presentation (the "spaghetti" model); a vectortopological (linear-node).

Topology is a branch of mathematics that studies the topological properties of figures, i.e. the properties, which do not change at any deformations made without ruptures and gluing together.

Vector-non-topological data presentation is a digital presentation of a point, linear, and polygonal spatial objects as a set of coordinate pairs with describing the objects geometry only.

Vector-topological presentation is a kind of vector presentation of linear and polygonal spatial objects, which describes not only their geometry, but also the topological relations between polygons, arcs, and nodes [12].

Fig.1. shows the structure of internal data of vector-non-topological or object GIS for the elementary electrical network consisting of 3 lines and 4 nodes.

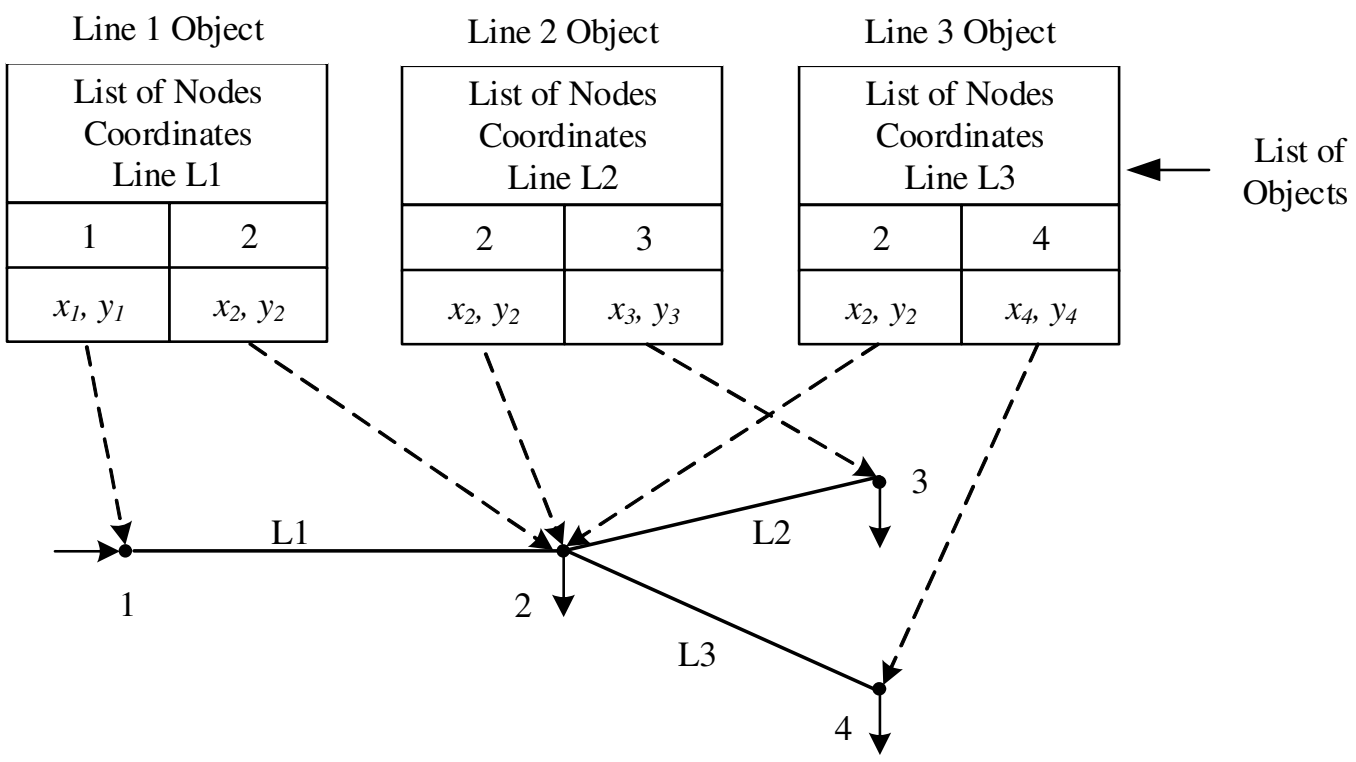

Fig. 1. Non-topological (object) data structure

As you can see in Fig. 1, each object (line) in the computer memory stores the coordinates $(x, y)$ of all nodes. The analysis of the non-topological data structure exposed the following shortcomings:

- redundancy in the information (uneconomical use of computer memory), i.e. the coordinates of the common node 2 are stored in the data structure of lines 12, 23, and 24;

- triple drawing (computer processor load), in an object GIS, each object is drawn completely; the program will draw the common node 2 three times.

Non-topological GIS include: the MapInfo (MapInfo Corp., USA); AtlasGIS (ESRI, USA) first versions and a large number of other systems. They are the systems with that all beginning GIS developers start their pilot projects. ArcInfo is a topological GIS.

In non-topological GIS, you can take an object or a part of it and move it to another location on the computer screen. Thus, it is clear that it is easy to perform such an operation, and the object readily leaves its neighbors. In topological GIS, an image is formed with interconnected elements, and connections between them can be broken in a result only of the distinct performance of these special operations.

At the time of creation of the first GIS, computer equipment was very inefficient, and the GIS developers decided to optimize the computer memory and save the processor operating time. Due to the savings, ArcInfo, the first linear-node topological GIS was developed. 
Nodal topology. Nodal topology is a transitional structure from non-topological to topological GIS. Many developers skip over this stage in their development and go directly to the implementation of a linear-node topology in their new version of GIS.

As you can see in Fig. 2, the same elementary electrical network is used, but the internal data structure has changed somewhat. Now all the points are included in one long list, and each object contains in its individual data structure only the links to the points from this list that denote its nodes. The nodal topology fully displays the topological connections of the electrical network diagrams.

When using the nodal topology, GIS does not really become topological in this case, since significant issues of spatial analysis cannot be solved with the nodal topology only.

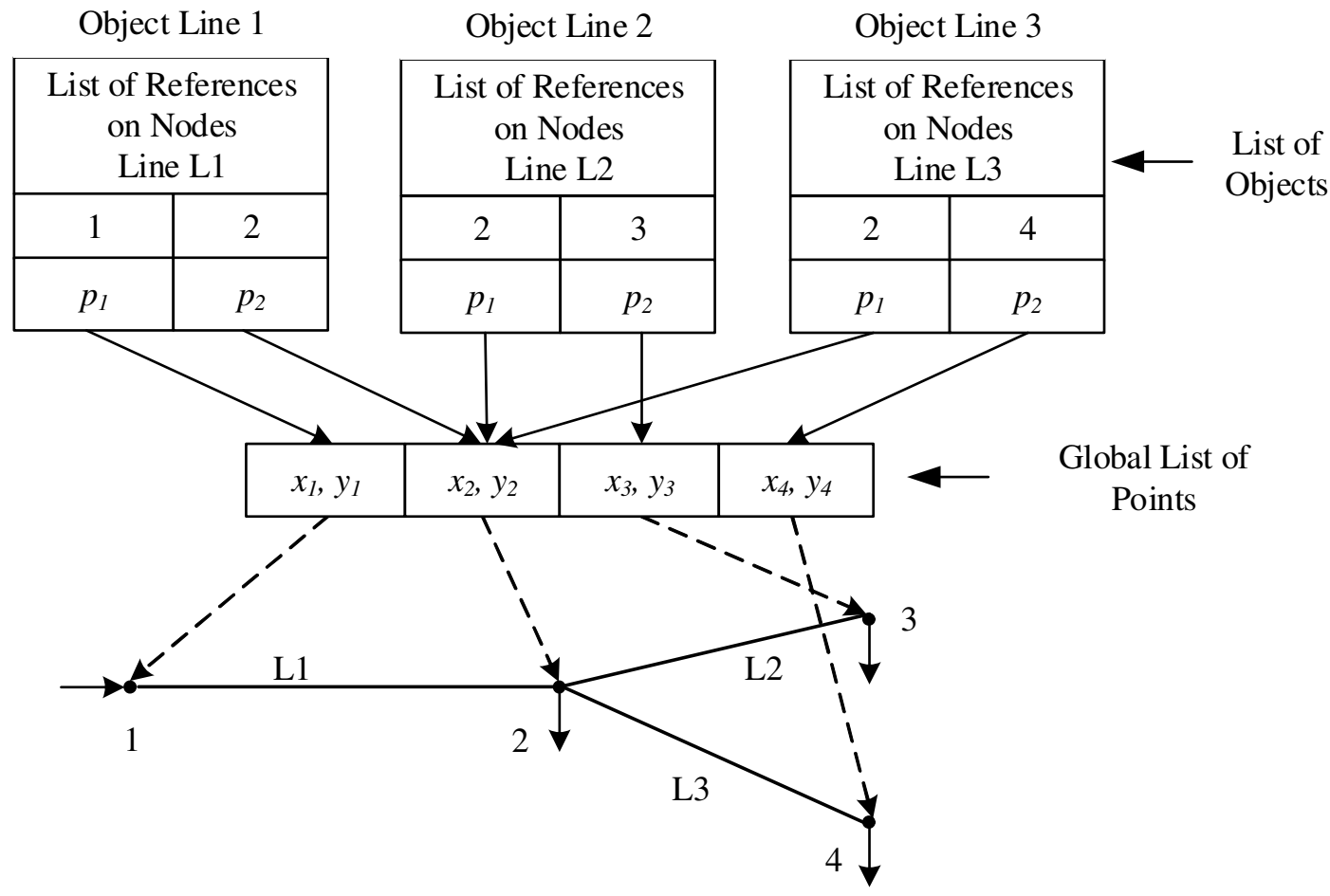

Fig. 2. Nodal data structure for elementary electrical network

Linear - nodal topology. Fig. 3 shows two polygons, but the polygon data structures are more mixed together in the groups of global memory descriptors. In addition to the global list of collected points (nodes), a global list of collected lines has appeared. In the "personal" structures of the polygons, only references are stored to the descriptors of the lines (edges) that make up the polygon. There are two references to the common edge L5 of two polygons from the data structure of polygon A1 and the data structure of polygon A2. And each structure encoding a line, as well as in an elementary nodal topology, has references to values with coordinates from a global list of points. The hierarchy of links occurs where the "leaves" are the coordinates (x, y) of points on the map.

The given data structure evidences impossibility to change the coordinates of a common point without deforming the adjacent objects. With getting benefits from memory savings, the global list of points took off the structural autonomy of the objects by creating difficulty of editing adjacent objects.

The solution of this problem is possible with the development of a special operation that provides opportunities to clone (create a duplicate) a common point in order to assign this copy to a detached polygon (it immediately enters the global list of points).

Thus, the linear-nodal topology is a good enough structure that handles spatial data, although it is a reflection of the technological insufficiency of computer technology. The advantage lies in its usability and functionality for many types of spatial analysis on maps. But it cannot deal effectively with the dynamic object maps. Object-oriented models are not available for it.

At date, object-oriented technologies are increasingly developing in the field of informatics and modeling. 


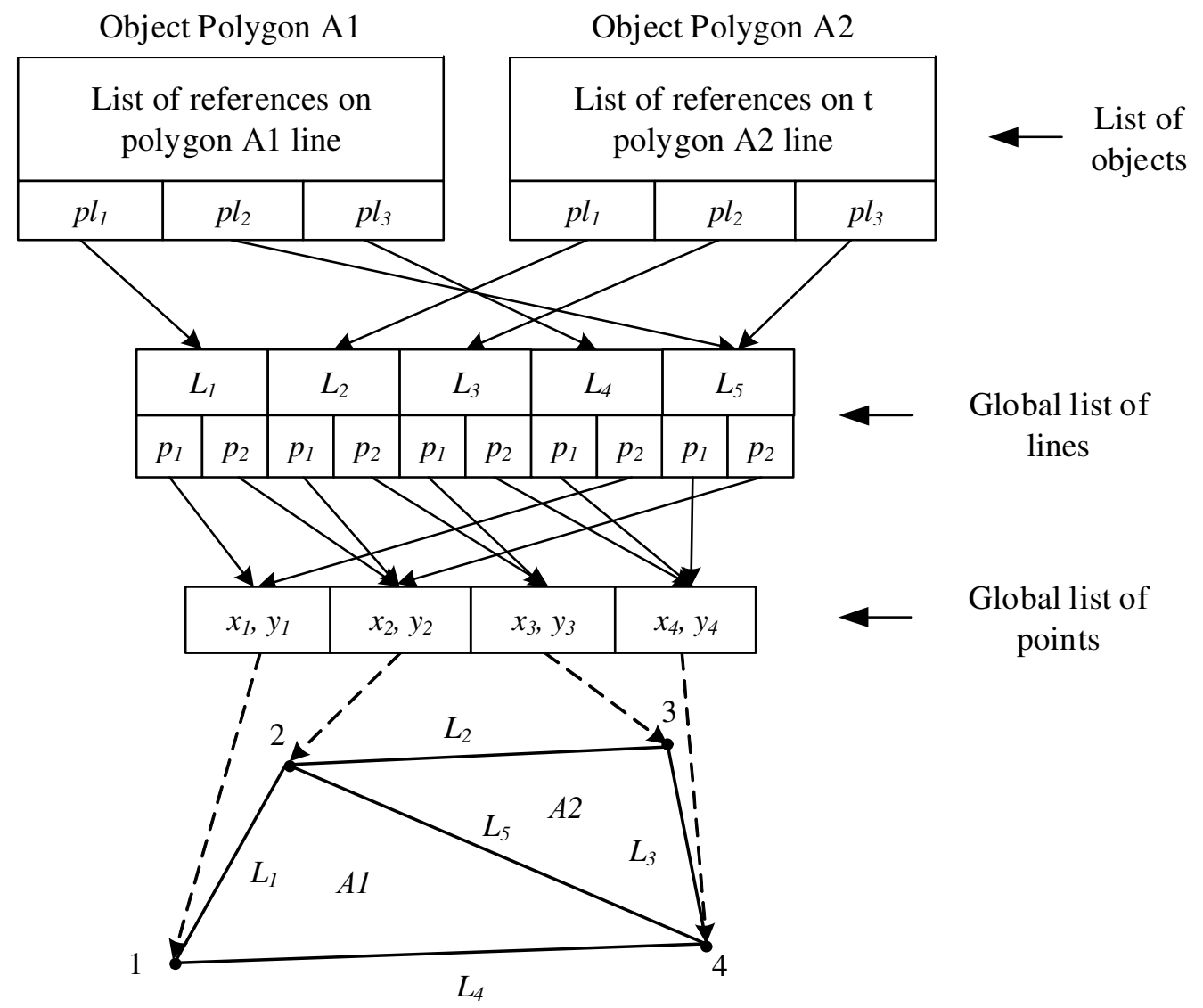

Fig. 3. Linear-nodal data structure for two polygons

Object-oriented programming (OOP) allows to reduce the project duration and labor intensity, improve reliability and reduce the software costs, in contrast to the traditional "procedural" programming method. In the electric power industry, OOP is used in the development of software for power distribution control systems in power supply (EMS) and distribution (DMS) networks, operational-managerial information complexes (SCADA), geo-information and other systems. When developing new software, the developers seek to take advantage of OOP.

Such systems are easier to use, the software will operate with user-friendly concepts such as wires, supports, transformers, switches, etc., and not with system-oriented concepts such as points, lines, polygons.

The GIS objectiveness is a much more productive concept than a linear-node concept, precisely in the field of topological problems, and it has a stronger potential during the development of objectoriented ideas.

For up-to-date GIS, an object-oriented, rather than a cartographic (topographic, topological, etc.) approach to describing a territory and objects on it should be primary. Complex objects support, inheritance of class properties, encapsulation, polymorphism, overlapping, overloading of functions (object models), etc. should be implemented. Object orientation is understood here not in the sense that GIS is recorded on the object-oriented means, but in the fact that the same mechanisms should be provided to the system user for data organizing.

The topological GIS provide insufficient support, or do not provide support at all for objectoriented domain models, and in object GIS, topological relations between objects can be represented in an incomplete form. Development of a hybrid object-topological GIS model is a highly relevant task [13].

A simplified data structure of object-topological GIS is shown in Fig. 4.

You can see in Fig. 4. the internal structure of two adjacent simple polygonal objects we drew earlier in Fig. 3. However, now it is supplemented with a table, where topological relations between objects are recorded (due to references to their topologically related parts). Of course, in reality, the 
object-topological structure has much more complicated organization in the computer memory than shown in Fig. 4.

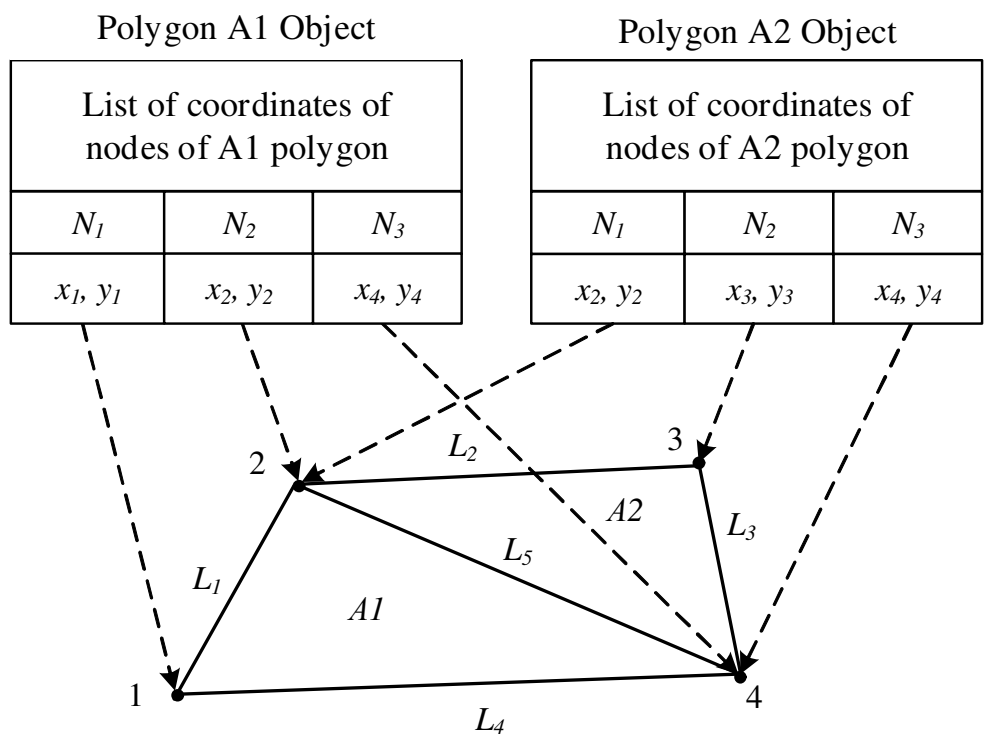

\begin{tabular}{|c|c|c|}
\hline \multicolumn{3}{|c|}{ List of topological relations } \\
\hline $\begin{array}{c}\text { Type of } \\
\text { relations }\end{array}$ & Element 1 & Element 2 \\
\hline TPO_node & $A_{1} \cdot N_{2}$ & $A_{2} \cdot N_{1}$ \\
\hline TPO_node & $A_{1} \cdot N_{3}$ & $A_{2} \cdot N_{3}$ \\
\hline TPO_line & $A_{1} \cdot N_{2}-N_{3}$ & $A_{2} \cdot N_{l}-N_{3}$ \\
\hline
\end{tabular}

Fig. 4. Object-topological data structure for two polygons

This structure allows combining all the properties of both topological and object digital maps. This structure shortcoming can be a wasteful use of the computer memory and processor time. With regard to the growth of computing power of the used hardware and the memory cheapening dynamics, it is necessary to consider the possible use of this structure.

The traditional view of topological relations establishment implemented in topological GIS is applied only to primitives or samples of objects. This is due to the fact that widely available in the market GIS are not object-oriented in the fullest sense. In object-oriented systems, we deal not only with the objects samples, but also with their classes, and these classes are not integrated multilevel constructions by implementing the mechanism of inheritance of properties.

For object-oriented GIS, there is the concept of conceptual topological relations (CTR), which extends topological relations to classes of objects [14]. In the limit, when a transition is made from a class (that is, a set of objects of the same type) to their samples, the CTR turn into traditional topological relations. The CTR build-up a multilevel system, since they are basics for the connections between the classes that also build-up multilevel structures. When using CTR in GIS, it becomes possible to make the user free from care to keep in mind the possibility of errors introduced into the relative position of objects of different classes on the map.

\section{Conclusions}

1. The GIS to be used in electrical networks should be based on a vector model of spatial data. The option of using as a raster substrate of maps of the area.

2. The advantages of the non-topological model are in the simplicity of the data structure, in the autonomy of the objects, allowing to turn to the object-oriented way of data organizing. The shortcomings are uneconomic use of the computer memory, computer processor loading, organization of topological relations by procedural means. The advantages of the topological model are saving of the computer memory and processor operation time, organization of topological relations in data structures. The shortcoming is the objects autonomy deprive.

3. The development of an object-topological data structure will allow combining the advantages of non-topological and topological GIS.

4. A more promising is the object-oriented way of presenting graphic information of electrical networks. Object orientation is understood here not always in the sense that GIS is recorded in object-oriented means, but that the same mechanisms (class property inheritance, encapsulation, polymorphism) should be provided to the system user for organizing data. 


\section{References}

[1] Christian Harder Enterprise GIS for energy companies. Published by Environment System Research Institute, Inc. ESRI Press. 1999. 110 p.

[2] Bill Meehan Empowering Electric and Gas Utilities with GIS. Published by Environment System Research Institute, Inc. ESRI Press. 2007. 280 p.

[3] GIS Best Practices. GIS for Renewable Energy. January 2010. ESRI Press. 46 p.

[4] Воротницкий В.Э., Моржин Ю.И. О концепции и практике использования геоинформационных технологий в электрических сетях (About the concept and practice of use of geoinformation technologies in electric networks). - Electrical stations, 2004, № 8. pp. 68-75. (In Russian).

[5] Yarosh V.A., Zhdanov V.G., Kobozev V.A., Logacheva E.A., Privalov E.E. Use of geoinformation systems for solving analytical problems in the power industry. Research Journal of Pharmaceutical, Biological and Chemical Sciences. vol. 10(1). 2019. pp. 1049-1055.

[6] Gomes F. V., Carneiro S. J., Pereira J. L. R., Vinagre M. P., Garcia P. A. N., Oliveira E. J., Araujo L. R., "A new distribution system reconfiguration approach using optimal power flow technique and sensitivity analysis for loss reduction," in: Proceedings of the IEEE Power Engineering Society General Meeting, San Francisco, USA, vol. 1, 2005, pp. 897-901.

[7] Horvat M., Vorsic J., Orgulan A., Skerbinek G. "Reduction of active losses with reconfiguration of electricity distribution networks," in: Proceedings of the IEEE Transmission and Distribution Conference, New Orleans, USA, vol. 1, 1999, pp. 154-159.

[8] Mohar T., Bakic K., Curk J. "Advanced planning procedure and operation of distribution network supported by SCADA and GIS," in: Proceedings of the IEEE Power Engineering Society Winter Meeting, Singapore, vol. 4, 2000, pp. 2780-2785.

[9] Boulaxis N. G., Papadopoulos M. P. "Optimal feeder routing in distribution system planning using dynamic programming technique and GIS facilities," IEEE Transactions on Power Delivery, vol. 17, no. 1, 2002, pp. 242-247.

[10] Ten C. W., Wuergler E., Diehl H. J., Gooi H. B. "Extraction of geospatial topology and graphics for distribution automation framework," IEEE Transactions on Power Systems, vol. 23, no. 4, 2008, pp. 1776-1782.

[11]Parikh P. A., Nielsen T. D. "Transforming traditional geographic information system to support smart distribution systems," in: Proceedings of the IEEE/PES Power Systems Conference and Exposition, Seattle, USA, 2009, pp. 1-4.

[12] Ю.Б. Баранов, А.М. Берлянт, Е.Г. Капралов и др. Геоинформатика. Толковый словарь основных терминов (Geoinformatics. Explanatory dictionary of basic terms) / Moscow: GISAssociation, 1999. 204 p. (In Russian).

[13]Ярош В.А. Представление пространственных данных электрических сетей в геоинформационных системах (Representation of spatial data of electrical networks in geographic information systems). Stavropol: NCSTU, 2007. 15 p. Deposited in All-Russian Institute of Scientific and Technical Information 31.10.2007, № 1016-B2007. (In Russian).

[14]Шпаков М.В. Разработка интеллектуальных геоинформационных систем на основе настраиваемой объектной модели предметной области (Development of intelligent geographic information systems based on a customizable object model of the subject area): abstract of dis.... cand. tech. sciences: Saint-Petersburg, 2004. 16 p. (In Russian). 